\title{
Challenges for the Use of Local Materials in Unbound Road Subbase in Qatar
}

\author{
Moaaz Hashim Mohamedain \\ moaaz@ashghal.gov.qa \\ Quality and Safety Department, Public Works Authority (Ashghal), Doha, Qatar
}

\author{
Khaled E. Hassan \\ khassan@irdme.net \\ Infrastructure Research \& Development (IRD QSTP-LLC), Doha, Qatar \\ Osman El-Hussain \\ osmane@ashghal.gov.qa \\ Quality and Safety Department, Public Works Authority (Ashghal), Doha, Qatar \\ Khalid Al-Emadi \\ kemadi@ashghal.gov.qa \\ Quality and Safety Department, Public Works Authority (Ashghal), Doha, Qatar
}

\begin{abstract}
Current practice in Qatar is to blend local limestone with dune sand for use in unbound pavement applications. Dune sand is used to improve the properties of fine aggregate and compliance with the QCS 2014 requirements of plasticity and sand equivalent. The material has been successfully used for many years but currently facing the challenge of limited dune sand supply and recent government restrictions on its use in construction. The paper presents data on the properties of limestone obtained from different sources, tested in accordance with the QCS 2014 requirements. Variation of limestone source and the presence of clay particles greatly affected its suitability for use in unbound pavement applications. Improvement could be achieved by adjusting the grading of the material. Recommendations are made to revise the QCS 2014 specifications within the context of international specifications, when the unbound material is placed in a dry environment and away from the water level to enhance the wider utilization of local materials and sustainable construction in Qatar.
\end{abstract}

Keywords: Local limestone aggregate; Pavement; Unbound subbase; Properties; Specifications

\section{INTRODUCTION}

Local limestone is currently used as unbound road base and subbase materials in Qatar. Qatar is underlain by geologically young rocks, principally of weak limestone with occasional bands of clay, and hence the properties of limestone could vary from different locations or even within the same source. The material has been successfully used in unbound pavement layers for many years. Due to the varying clay type and content, the material is generally blended with dune sand, gabbro fines and/or cement to improve its properties (Hassan et al., 2015). The road subbase acts as a platform for the construction of the upper pavement layers and provides protection of the subgrade material. It is generally made of a compacted granular material with improved properties and quality compared to the subgrade. The Qatar Construction Specification (QCS, 2014) specifies physical and chemical properties for unbound road subbase materials. 
This paper covers the characterization of granular subbase materials, being used in selected Ashghal pavement projects. Samples were collected from five (5) sources and tested for compliance with the QCS 2014 requirements. Recommendations are made for the development of performance data to support the wider use of local materials in construction.

\section{MATERIALS AND TESTING PROGRAMME}

Samples of granular materials were collected from different sources in Qatar between October 2018 and February 2019. A total of five (5) sources for subbase materials (S1 to S5) were considered in the investigation. Six (6) samples were collected from sources S1 to S3, whereas three (3) samples were used from sources S4 and S5. The materials tested in this investigation were claimed to be compliant with the QCS 2014 requirements for use in unbound subbase application. Although no information was provided on the composition of the supplied materials, it is believed that all the materials were composed of local limestone mixed with different quantities of dune sand in the range of $5-20 \%$ by weight.

The testing programme followed the compliance tests given in the QCS 2014, Section 6, Part 4 for unbound road subbase materials. Testing was conducted in the Ashghal Research \& Development Centre in Najma, and included:

1. Grading (ASTM D6913, 2017) and Fines Content (ASTM D1140, 2017).

2. Sand Equivalent (ASTM D2419, 2014).

3. Liquid Limit (LL) and Plasticity Index (ASTM D4318, 2017, Method A for the LL).

4. Maximum Dry Density and Optimum Moisture Content (ASTM D1557, 2012).

5. CBR and Swelling (ASTM D1883, 2016).

6. Loss of Abrasion (ASTM C131, 2014).

7. Fractured Faces (ASTM D5821, 2017) and Flat and Elongated Particles (ASTM D4791, 2019).

8. Soundness (ASTM C88, 2018).

\section{RESULTS}

A summary of the test results is given in Table 1, together with the QCS 2014 specified limits. Each value represents the average of 6 tested samples for sources S1, S2, and S3, whereas the average of 3 tested samples for S4 and S5.

\subsection{Grading and Fines Content}

Sieve analysis testing (Grading (ASTM D6913, 2017)) and Fines Content (ASTM D1140, 2017)) was conducted on the materials received from the five (5) sources and the average grading results are shown in Figure 1. The grading results showed good compliance with the grading envelope specified in the QCS 2014. The average grading curves show that materials from sources S1, S2, S3, and S5 showed full compliance with the grading envelope whereas only S4 marginally failed to meet specific sieve sizes. The S4 curve shows almost a single size grading with a slightly higher value for coarse aggregate (sieve $25 \mathrm{~mm}$ ) than the maximum specified, and a marginally lower value for fine aggregate (sieve $2 \mathrm{~mm}$ ) below the minimum specified limit. The S4 material would 
have benefited from the addition of dune sand to improve its grading and compliance with the QCS 2014.

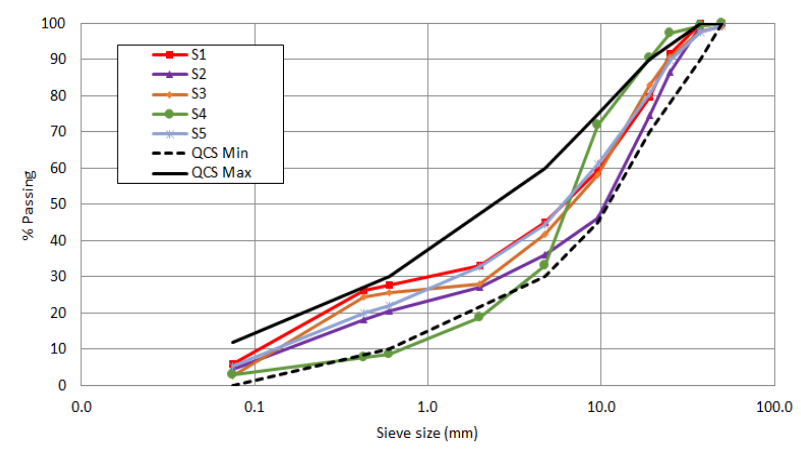

Figure 1: Sieve analysis of subbase materials from different sources

Materials from sources S1 and S3 showed signs of gap grading, presumably due to the addition of an excessive amount of dune sand. The S5 grading fell within the mid-range of the QCS 2014. Maintaining a continuous grading curve within the overall grading envelope is important to ensure good compaction of the subbase. Improved quality control for the production of local limestone, including blending with other materials to improve plasticity and SE requirements, could easily produce compliant gradings for unbound subbase applications.

Table 1: A summary of subbase results from different sources

\begin{tabular}{|l|c|c|c|c|c|c|}
\hline Parameter & S1 & S2 & S3 & S4 & S5 & $\begin{array}{c}\text { QCS 2014 } \\
\text { limits }\end{array}$ \\
\hline Sand equivalent, \% & 70 & 20 & 23 & 45 & 33 & 25 min \\
\hline Liquid limit, \% & $\mathrm{NP}$ & $\mathrm{NP}$ & $\mathrm{NP}$ & $\mathrm{NP}$ & $\mathrm{NP}$ & $25 \mathrm{max}$ \\
\hline Plasticity index, \% & $\mathrm{NP}$ & $\mathrm{NP}$ & $\mathrm{NP}$ & $\mathrm{NP}$ & $\mathrm{NP}$ & $6 \mathrm{max}$ \\
\hline $\mathrm{MDD}, \mathrm{Mg} / \mathrm{m}^{3}$ & 2.08 & 2.32 & 2.03 & 2.04 & 2.16 & $2.05 \mathrm{~min}$ \\
\hline OMC, \% & 8.0 & 4.7 & 8.4 & 9.2 & 6.9 & - \\
\hline CBR, \% & 212 & 177 & 106 & 110 & 122 & 70 min \\
\hline Swell, \% & 0.0 & 0.5 & 0.3 & 0.0 & 0.0 & $1.0 \mathrm{max}$ \\
\hline Loss by abrasion, \% & 31 & 26 & 33 & 20 & 23 & $40 \mathrm{max}$ \\
\hline Fractured faces, \% & 100 & 100 & 100 & 100 & 100 & 50 min \\
\hline Flat and elongated, \% & 0 & 0 & 0 & 1 & 0 & 15 max \\
\hline Soundness, \% & 4.2 & 0.9 & 11.9 & 2.2 & 2.1 & 20 max \\
\hline
\end{tabular}

\subsection{Sand Equivalent, Liquid Limit and Plasticity Index}

In general, high plasticity values could lead to problems due to swelling and shrinkage, while aggregates with low plasticity tend to be highly susceptible to changes in moisture content. The QCS 2014 specifies a minimum value of 25 for the Sand Equivalent (SE) of unbound subbase materials (ASTM D2419, 2014). The results in Table 1 for sources S1, S4, and S5 satisfied the QCS requirement, whereas samples from source S2 and S3 failed the test.

In contrast to the SE, the plasticity parameters of Liquid Limit (LL) and Plasticity Index (PI) show that all the tested samples are Non-Plastic (NP). Comparing the SE and plasticity results with sieve size analysis show that source $\mathrm{S} 1$ exhibited the highest sand content, passing $4.75 \mathrm{~mm}$, as well as the highest contents of particles passing 0.425 and $0.075 \mathrm{~mm}$. These materials gave the highest values of SE with NP behavior. Source S3 also showed NP behavior with similar grading of fine aggregate to source S1, even with 
less fines passing $0.075 \mathrm{~mm}$, but gave low SE values. The comparisons indicate no direct relation between the grading of fine aggregates and the SE and plasticity results.

\subsection{Maximum Dry Density and Optimum Moisture Content}

The Maximum Dry Density (MDD) is obtained in the laboratory at the Optimum Moisture Content (OMC). The OMC in turn depends on the grading and fines content of the material, as a finer grading tends to increase the OMC due to the increased surface area of the particles. The presence of swelling clay would also increase the demand of moisture. For the unbound subbase materials, the QCS specifies a minimum value of MDD of $2.05 \mathrm{Mg} / \mathrm{m}^{3}$, a field density of $100 \%$ of the MMD, and in place moisture content within $\pm 2.0 \%$ of the OMC. The results in Table 1 show that the MDD results ranged from 2.03 to $2.32 \mathrm{Mg} / \mathrm{m}^{3}$ for the subbase samples tested from different sources. The highest MDD was found for source S2, which also exhibited the lowest OMC of 4.7\%. The low OMC of source S2 does not match with the failed SE results, which indicate the presence of expansive clay. The highest OMC of $8.4 \%$ and $9.2 \%$ are found for sources S3 and S4 respectively, which are associated with the lowest values of MDD below the minimum specified limit of $2.05 \mathrm{Mg} / \mathrm{m}^{3}$.

\subsection{CBR and Swelling}

The load-bearing capacity of pavement layers is generally determined from the CBR, which is an important parameter for pavement designs. The results of CBR and swelling are also summarized in Table 1. For unbound subbase materials, the QCS 2014 specifies a soaked CBR of minimum $70 \%$ and a maximum swelling of $1.0 \%$ (ASTM D 1883, 2016). The CBR values ranged from 106 to $212 \%$ for the samples tested from different sources, at least $50 \%$ above the minimum specified value. The swelling was relatively small for all tested specimens, maximum $0.3 \%$. Source S2 was the only exception to give a slightly higher value of $0.5 \%$, still below the maximum QCS specified value of $1.0 \%$.

The compliance of the swelling and plasticity results with the QCS 2014 specification contradicts the SE results, especially for sources S2 and S3, which failed to meet the QCS requirement for SE. This finding may raise a question on the suitability of the SE test to assess the quality of fines for unbound pavement materials.

\subsection{Loss by Abrasion}

Aggregate abrasion characteristics are important for pavement materials to provide adequate resistance to crushing, degradation and disintegration under traffic loadings. The abrasion results are given in Table 1 for the subbase samples tested from different sources. The QCS 2014 specifies a maximum loss by abrasion of $40 \%$ for unbound subbase materials (ASTM C131, 2014).

The results show that all tested materials complied with the QCS requirement. The highest values (31 and 32\%) were for materials supplied from sources S1 and S3, respectively. The lowest loss by abrasion value of $20 \%$ was for source S4.

\subsection{Flat and Elongated Particles and Fractured Faces}

Flat and elongated particles tend to fracture more easily than cubical and circular aggregate particles, and are more difficult to compact on site. Fracture faces are more 
related to the angularity of coarse aggregate, which is important to ensure adequate aggregate interlock and prevent excessive deformation under loadings. The flat and elongated particles were $1 \%$ or less for all materials supplied from different sources and far lower than the maximum 15\% specified in QCS 2014 (ASTM D4791, 2010). The fractured faces were 100\% for all tested samples, doubled the QCS 2014 minimum specified value of $50 \%$.

\subsection{Soundness}

The soundness of aggregate is related to its durability to resist disintegration by weathering due to wetting and drying and freeze-thaw actions. For subbase materials, the QCS specifies a maximum permissible weight loss of $20 \%$ after the soundness test ( 5 cycles of magnesium sulfate) (ASTM c88, 2018). The results in Table 1 show soundness values between 1 to $12 \%$, lower than the maximum specified value. The highest soundness of $12 \%$ is found for materials supplied from source S3, which also exhibited the highest loss of abrasion.

\section{DISCUSSION OF RESULTS}

Qatar lacks quality aggregate and the construction industry relies mainly on imported aggregate for use in asphalt and concrete. Local limestone, blended with dune sand, has been successfully used for unbound pavement applications. Due to the limited availability of dune sand, the government has recently restricted its use in construction, and therefore there is a need to revise the compliance of local materials with construction specifications and to consider other options to widen the use of local resources. The results in Table 1 for subbase materials showed high variability of the properties of local limestone supplied from different sources. In terms of compliance, the most critical properties that could influence the acceptance or rejection of local limestone materials are the sand equivalent (SE) and plasticity (LL and PI), which are related to the quality of fines.

Two (2) sources, out of the five (5) sources investigated, were found to be noncompliant with the QCS 2014 requirements for SE. The non-compliant SE results were contradictory to the plasticity results. Materials from S2 and S3 failed the SE requirement, while the properties of plasticity and swelling were compliant. If expansive clay is present in the material, it would be expected that the material would exhibit high plasticity, absorb more water to reflect high OMC, and show high swelling values.

The LL and PI are widely used worldwide in pavement specifications to classify fine grained soils into different degrees of plasticity, ranging from low for silty soils to extremely high for clayey soils. The decision of whether to reject a subbase material marginally failing the SE should be discussed within the overall material compliance with other requirements and project-specific conditions. Road Note 31 (TRL, 1993) recommends higher LL and PI limits than currently specified in the QCS 2014, for granular subbases in arid and semi-arid climates, provided that the subbase is at least $1 \mathrm{~m}$ above the groundwater level. Assuming the subbase material is used in a site where the ground water is low, there could be a case to consider relaxing QCS 2014 plasticity requirements for this specific site/project.

As defined in ASTM D2419 (2014), the SE test gives an indication of the relative 
proportions of clay-size or plastic fines and dust in granular soils and fine aggregates that pass the 4.75-mm (No. 4) sieve. The suitability of the SE test to assess the quality of fines has been investigated by different researchers. Felekoglu (2008), reported that the SE test cannot differentiate between clay and silt particles, and that the Methylene Blue (MB) test is more appropriate for assessing the quality of fines. Similarly, Black (2009) indicated the same downsides of the SE test, and concluded the application of the SE test alone could lead to the acceptance of an unsuitable or to the rejection of suitable aggregates. Nikolaides et al. (2007) studied the properties of aggregate from different sources in Greece and found that aggregates that do not satisfy the SE requirement could still be suitable for use in highway engineering. They recommended the importance of including the MB test for assessing the quality of fines.

Recycled materials of excavation and construction waste could provide a sustainable alternative for unbound pavement layers. Recycled materials were used for the construction of an access road to the Rawdat Rashid landfill site in 2014, with satisfactory performance (Hassan et al., 2015). The road comprised of three adjacent subbase sections of excavation waste, crushed concrete, and a control section made of local limestone with $20 \%$ dune sand. Both the excavation waste and control subbase sections failed the SE. In-situ testing of density, surface modulus and rutting indicated excellent performance for the three subbase sections. As per the UK Specification for Highway Works, the three subbase sections would be suitable for traffic loading up to 80 million standard axles (Highways England, 2016).

There is no evidence from the results presented in this report that materials failing to meet the SE will not perform in service. It is therefore recommended to consider assessing the performance of subbase constructed with materials that failed the SE, and compare it with the QCS 2014 requirements. Such a revision of the national construction specifications will ensure that local materials are effectively used in construction and support the government strategy of sustainable development.

\section{CONCLUSION AND RECOMMENDATIONS}

This paper presents the characterization of unbound subbase materials for use in pavement construction. Based on the results, the following conclusions and recommendations are made:

- The properties of local limestone varied widely for materials supplied from different sources, with general compliance with the QCS 2014 requirements for use as unbound subbase.

- Materials failed to meet with the QCS specifications mainly in relation to the grading and sand equivalent.

- The non-compliant grading was related to specific sieve sizes, slightly outside the specified envelope, which could be adjusted at production with improved quality control.

- The use of dune sand to improve the quality of fine particles could put the grading marginally out of specifications, particularly for sieve sizes 0.6 and $0.425 \mathrm{~mm}$.

- Inconsistent results were obtained from the plasticity and SE results for assessing the quality of fine particles in unbound materials.

- Unbound subbase materials, which failed the sand equivalent, exhibited accepted 
swelling results, with no evidence of harmful and expansive clay.

- Subbase materials satisfied the QCS 2014 requirements of CBR, loss by abrasion, particle shape and soundness.

- More work is required to improve the production of unbound subbase materials, mainly grading, and to assess the suitability of the SE as a pass/fail test in QCS 2014.

\section{REFERENCES}

ASTM C131/C131M (2014). Standard Test Method for Resistance to Degradation of Small-Size Coarse Aggregate by Abrasion and Impact in the Los Angeles Machine. ASTM International, the USA.

ASTM C88 (2018). Standard Test Method for Soundness of Aggregates by Use of Sodium Sulphate or Magnesium Sulphate. ASTM International, the USA.

ASTM D1140 (2017).Standard Test Methods for Determining the Amount of Material Finer than 75- $\mu \mathrm{m}$ (No. 200) Sieve in Soils by Washing. ASTM International, the USA.

ASTM D1557 (2012). Standard Test Methods for Laboratory Compaction Characteristics of Soil Using Modified Effort $\left(56,000 \mathrm{ft}-\mathrm{lbf}_{\mathrm{ft}} \mathrm{ft}^{3}\left(2,700 \mathrm{kN}-\mathrm{m} / \mathrm{m}^{3}\right)\right)$. ASTM International, the USA.

ASTM D1883 (2016). Standard Test Method for California Bearing Ratio (CBR) of LaboratoryCompacted Soils. ASTM International, the USA.

ASTM D2419 (2014). Standard Test Method for Sand Equivalent Value of Soils and Fine Aggregate. ASTM International, the USA.

ASTM D4318 (2017). Standard Test Methods for Liquid Limit, Plastic Limit, and Plasticity Index of Soils. ASTM International, the USA.

ASTM D4791 (2019). Standard Test Method for Flat Particles, Elongated Particles, or Flat and Elongated Particles in Coarse Aggregate. ASTM International, the USA.

ASTM D5821-13 (2017). Standard Test Method for Determining the Percentage of Fractured Particles in Coarse Aggregate. ASTM International, the USA.

ASTM D6913 / D6913M (2017). Standard Test Methods for Particle-Size Distribution (Gradation) of Soils Using Sieve Analysis. ASTM International, the USA.

Black, M. P. (2009). Geologic inventory of North Island aggregate resources: Influences on Engineering Materials Properties. Geology, School of the Environment, The University of Auckland, North Island. Available at https://www.aqa.org.nz/uploads/files/North\%20 Island\%20Geological\%20Inventory\%202009.pdf.

Felekoglu, B. (2008). A comparative study on the performance of sands rich and poor in fines in self-compacting concrete. Construction and Building Materials, Vol. 22, Issue 4.

Hassan K. E., Reid, J. M. \& Al-Kuwari, M. S. (2015). Use of recycled and secondary aggregates in Qatar - Guidance document. (TRL Published Project Report PPR736). TRL Limited, Crowthorne, the UK. Available at http://www.trl.co.uk/reports-publications/ report/?reportid=7013.

Highways England (2016). UK Specification for Highway Works, Series 800 Road Pavements - Unbound, cement and other hydraulically bound mixtures. Manual of Contract Document for Highway Works Volume 1. Highway England, London, the UK. Available at http://www. 
standardsforhighways.co.uk/ha/standards/mchw/vol1/pdfs/MCHW\%20800.pdf.

Nikolaides, A. S., Manthos, E. \& Sarafidou, M. (2007). Sand equivalent and Methylene blue value of highway engineering. Aristotle University of Thessaloniki, Department of Civil Engineering, Thessaloniki, Greece.

QCS (2014). Qatar Construction Specifications. Ministry of Municipality \& Environment, Qatar Standards, Doha, Qatar.

TRL (1993). A guide to the structural design of bitumen-surfaced roads in tropical and subtropical countries. (TRL Overseas Road Note 31). TRL Limited, Crowthorne, the UK. 